\title{
Organizing Medical Care Programs to Meet Health Needs
}

\author{
By Avedis Donabfidin and S. J. Axelrod*
}

\begin{abstract}
Medical care in the United States is organized around a large number of agencies both governmental and nongovernmental, with insufficient co-ordination among them and no effective machinery for over-all planning. There are shortages and maldistribution of both personnel and facilities. The rise in specialization has resulted in continued decline in the number and status of the family physician. Organized group practice, which may offer one possible answer to the fragmentation and depersonalization of medical care, has increased, but not to the extent of making a significant impact on the prevailing solo, fee-for-service pattern of medical practice. Hospitals face especially acute problems in the form of rapidly increasing costs and shortages of staff. Facilities for the care of the chronically ill and aged are insufficient in number and the care they offer is often far from adequate. Some trends that may presage a more rational organization of medical services are the concentration of community medical resources in and around voluntary hospitals; the differentiation of care within hospitals to fit patient needs more closely; the development of hospital-based services for ambulatory and homebound patients; and increasing consideration to the establishment of closer relationships among hospitals, nursing homes, and other facilities serving a given region.
\end{abstract}

Avedis Donabedian, M.D., M.P.H., Ann Arbor, Michigan, is Associate Professor of Public Health Economics and Research Associate, Bureau of Public Health Economics, School of Public Health, University of Michigan. He was formerly on the staffs of the New York Medical College and Harvard University School of Public Health. He is coauthor of Medical Care Needs and Services in the Boston Metropolitan Area (1957).

S. J. Axelrod, M.D., M.P.H., Ann Arbor, Michigan, is Professor of Public Health Economics and Director, Bureau of Public Health Economics, School of Public Health, University of Michigan. He is coauthor of Comprehensive Physicians' Services Under Voluntary Health Insurance (1958) and a contributor to journals in the medical care field.

* Julia Attwood, Research Assistant, Bureau of Public Health Economics, gave valuable assistance in the preparation of this paper. 
$\mathrm{O}^{\mathrm{N}}$ $\mathrm{N}$ first examination, our system of medical care appears to be a rather incoherent aggregate of elements taking a variety of forms and placed under a multiplicity of auspices. Despite this apparent lack of design, a pattern is discernible in the form of a major cleavage between governmental and private sponsorship. The private sector is seen to be further differentiated. There are, on the one hand, entrepreneurial efforts, both large and small, by persons and institutions conducting, as it were, a commerce in health services. On the other hand, there is a system of nonprofit institutions, such as the voluntary hospital, which trace their origins to the charitable impulses of the community. These institutions, while nongovernmental, are under community sponsorship and are expected to respond to community need rather than solely to market place considerations. There is a great deal of overlapping, as would be expected, in the activities of the various subsystems, and there is constant interaction among them.

The principal, though informal, system of providing care still revolves around the private practice of physicians and their referral of patients to other health resources. Closely associated are the insurance programs which finance an increasing portion of the private medical bill. Concentrating upon hospital care and, to a lesser extent, physicians' services in the hospital, these programs met 53 per cent of private expenditures for hospitalization in 1959 and 29 per cent of the cost of physicians' care. ${ }^{1}$ This means that patients had to pay directly on an out-of-pocket basis an additional $\$ 2.1$ billion for hospitalization, $\$ 3.2$ billion for physicians' services, $\$ 3.6$

1 Agnes W. Brewster, "Voluntary Health Insurance and Private Medical Care Expenditures, 1948-59," Social Security Bulletin, Vol. 12 (Decembcr 1960), pp. 4, 11. billion for drugs, and $\$ 4.2$ billion for other health services such as dental care, nursing home care, and appliances. In fact, health insurance covered only 24 per cent of private expenditures for medical care, which totalled $\$ 18.3$ billion in 1959. Of a total of $\$ 24.1$ billion representing both private and public expenditures for health and medical care services in fiscal $1958-1959$, only 17 per cent was met by health insurance financing.

Government involvement in the provision and financing of medical care is considerable and now represents about a quarter of our national expenditures for health and medical care services. Nevertheless, our governmental medical care programs appear to be little more than a patchwork created to meet urgent needs. These programs establish patterns which are modified only in response to social pressures which can no longer be ignored.

Government has assumed a measure of responsibility for selected population groups-members of the armed forces and their dependents, veterans, merchant seamen, federal employees, and Indians; certain disease categoriesmental illness, tuberculosis, crippling in children, and disabling employment handicaps in adults; and for recipients of public assistance including the medically indigent aged. In some of its programs, government provides health services directly; in others, it accepts financial responsibility for care furnished by private and community health resources; in still others, it combines the two approaches. Moreover, federal, state, and local governments sponsor some programs separately and others jointly. Participation in governmental programs is carefully hedged by all manner of limitations on eligibility. The range of services provided varies from the fairly broad to the very lim- 
ited, but, except for the armed forces, usually falls far short of being comprehensive.

But programs, formal or informal, governmental or private, are only frameworks within which health care is provided. Crucial to any program are the health personnel and facilities available to provide service.

\section{Personnel}

In 1959 there were 236,089 physicians in the United States, 133.4 physicians per 100,000 population. ${ }^{2}$ This ratio has remained virtually unchanged since 1940. This remarkable stability in manpower has been maintained in the face of greatly increased utilization of physicians' services. Thirty years ago, the average person saw a physician two or three times a year; now the annual average is five. ${ }^{3}$

In the past, there was controversy over the shortage of physicians. It was argued that the modern physician, armed with more effective techniques and supported by auxiliaries, was fully able to cope with the increased demand on his services. It is now all too apparent that, simply in order to keep pace with our population growth, the supply of physicians must be greatly increased. The American Medical Association's Council on Medical Education and Hospitals has indicated a need for 10,000 medical school graduates in 1975 , about 3,500 more than our present output. Even though existing medical schools are expanded, "it appears likely that at least 10 new medical schools with an average graduating class of 100 students

2 U. S. Public Health Service, Health Manpower Source Book, Section D: Physicians' Age, Type of Practice, and Location (Washington: U. S. Government Printing Office, 1960), p. 2.

${ }^{3}$ U. S. National Health Survey, Health Statistics: Volume of Physician Visits, United States, July 1957-June 1959 (Washington: U. S. Government Printing Office, 1960), p. 2. will be required." 4 This expansion, even if realized, would only maintain the physician-population ratio at the level prevailing for the last twenty years. It will not begin to meet the need for additional physicians in medical education, public health, industrial medicine, and psychiatry. For example, in order to meet the minimum requirements of the American Psychiatric Association, our mental hospitals would need twice as many physicians, four-fifths again as many nurses, and two-thirds again as many social workers as they now have. ${ }^{5}$

The inequalities in physician distribution that have existed for several decades in the United States are still with us. There are striking regional and rural-urban differences which cannot be accounted for by differences in need for physicians' services. A major difference between urban and rural areas is the relative lack of specialists in the latter. Inadequacies of supply and inequalities in distribution are also to be seen with respect to other health personnel, especially dentists and nurses.

Specialization is increasingly evident in medical practice. Twenty years ago, 24 per cent of physicians in private practice were classified as full-time specialists; now, the proportion stands at 49 per cent. ${ }^{6}$ However, despite the relative decline in numbers and status, the general practitioner is still very important in providing medical care. In 1958 about three-quarters of a national sample of the adult population asked to name their family physician or the physician to whom they would go first

${ }^{4}$ American Medical Association, Council on Medical Education and Hospitals, "Medical Education in the United States and Canada," Fifty-ninth Annual Report, Journal of the American Medical Association, Vol. 171 (November 1959), p. 1509.

${ }^{5}$ George D. Albee, "The Manpower Crisis in Mental Health," American Journal of Public Health, Vol. 12 (December 1960), pp. 18951896.

${ }^{6}$ U. S. Public Health Service, op. cit., p. 2. 
in case of illness named a physician in general practice. $^{\tau}$ But the other side of this coin is equally significant. The survey revealed that about one adult in five would consult a specialist first in case of illness. In metropolitan areas, as many as one out of three family physicians named were, in fact, specialists.

The high standards of professional competence associated with specialization are greatly prized. But specialist care can become episodic, impersonal, too much preoccupied with narrowly defined medical problems, and too little concerned with the patient as a whole. Some way is needed for making available at one and the same time care of the highest professional competence, a unifying medical management, and a stable, empathic relationship satisfying both to patient and physician. What we seek is a synthesis of the modern specialist and the traditional, idealized family physician. Can it be formed within one physician no matter how richly endowed? Can it be approximated through some organizational device?

Solo, fee-for-service, private practice of medicine remains the predominant pattern in the United States. Excluding inactive physicians and interns and residents, 81 per cent of all physicians are engaged in private practice. But even this deep-rooted tradition seems to be giving way before the increasing organizational complexity of modern society. A survey of physicians graduated in 1945 showed that ten years later 27 per cent of them had full-time salaried posts. $^{8} \quad$ It is estimated that at least one third of physicians now draw some income from salary, and it is likely that

${ }^{7}$ Health Information Foundation, "A View of Our Family Physicians," Progress in Health Services, Vol. 7 (June 1958), p. 2.

${ }^{8}$ Herman G. Weiskotten, "Trends in Specialization," Journal of the American Medical Association, Vol. 160 (April 14, 1956), p. 1305. this proportion will increase in future years. ${ }^{9}$

The individual, entrepreneurial form of medical practice, financed by a graduated, fee-for-service levy on the individual patient, is an intractable organism not readily amenable to social planning or professional controls. Curiously enough, it is this same quality that is both highly prized by its champions and deplored by its critics.

Thirty years ago, the Committee on the Costs of Medical Care envisaged medical groups financed by some form of prepayment as the basic structural unit of our medical care system. When polled during the last year of World War II, over half the physicians about to be demobilized indicated that they wished or intended to join medical groups on their return to civilian life. ${ }^{10}$ Events have fallen far short of these expectations.

Hunt and Goldstein define a medical group as "a formal association of three or more physicians providing services in more than one medical field or specialty, with income from medical practice pooled and redistributed to the members according to some prearranged plan. ${ }^{11}$ According to this definition, in 1932 there were some 236 groups with 1,466 full-time physicians in this country. A more recent survey in 1959 identified 1,154 groups with 10,085 full-time physicians. $^{12}$ This means that cur-

9 "Forecast for 1966," Medical Economics, Vol. 33 (August 1956), p. 134.

${ }^{10}$ Edwin P. Jordan, "Group Practice," New England Journal of Medicine, Vol. 250 (April 1, 1954), p. 558.

${ }^{11}$ G. Halsey Hunt, Marcus S. Goldstein, Medical Group Practice in the United States: A Summary of Recent Published Material and Supplementary Unpublished Data on Fees and Volume of Work (Public Health Service Publication No. 77) (Washington: U. S. Government Printing Office, 1951), p. 1.

$12 \mathrm{~S}$. D. Promrinse and M. S. Goldstein, Group Practice, Vol. 9 (November 1960), p. 850 . 
rently about 6 per cent of all physicians in private practice are engaged in fulltime group practice. While group practice constitutes a potentially important type of medical care organization, currently it falls very short of fundamentally altering the predominant solo pattern of medical practice in this country.

Much research needs to be done before one may speak with confidence about the advantages and disadvantages of group practice. Meanwhile, advocates of group practice assert that this is an organizational form ideally suited to the solution of many of the problems in medical care we face today. By bringing together physicians of diverse and highly developed skills and putting at their disposal the facilities modern medicine requires, group practice makes possible the provision of competent and appropriately co-ordinated medical care at prices patients can afford. As an organizational form, group practice is much more amenable to social planning and innovation than is the solo practice form of medicine. It permits more efficient use of manpower by fully utilizing the recently qualified physician and supplementing his efforts by those of auxiliary personnel. It lends itself much more readily to financing a wide range of services through prepayment. It enables the incorporation of safeguards to ensure quality of care, and it promotes on-the-job education of physicians and other professional personnel. And, while it introduces an element of organizational restraint into the individual physician's practice which not all physicians find congenial, group practice does allow physicians to run their own affairs and to retain a large degree of collective control over their professional interests.

Many believe that group practice can solve successfully the patient's dual and often concurrent needs for the general- ist and the specialist. One physician within the group, in some cases a general physician, in other cases, a specialized internist, is selected by the patient as his family doctor. This physician serves as the central source of care for the patient but is able to call on and co-ordinate all the resources of the group as the need arises. The Montefiore Medical Group has taken one further step in elaborating and testing this concept of joint responsibility for personal care of the patient..$^{13}$ On a demonstration basis, a sample of this group's patients have received supervision and care by an internist, a social worker, and a public health nurse who jointly function as some kind of composite family physician. Whether these organizational devices will satisfy the need for a personal physician that many patients seem to feel remains to be seen.

\section{Hospitals}

Hospitals occupy a central position in the organization of medical care in this country. They constitute an immense establishment of about 7,000 institutions containing more than 1.5 million beds. ${ }^{14}$ With total assets of $\$ 17$ billion and yearly operating costs of almost $\$ 8$ billion, hospitals are big business by any standard.

In keeping with our general pattern of medical care, government and voluntary organizations share control and operation of hospitals. All levels of government are involved to the extent of owning one third of all institutions with two-thirds of all beds. In fact, government has accepted nearly total responsibility for hospitals for the care

${ }^{13}$ George A. Silver, "Social Medicine at the Montefiore Hospital: A Practical Approach to Community Health Problems," American Journal of Public Health, Vol. 48 (June 1958), pp. 724-731.

${ }^{14}$ Guide Issue. Journal of the American Hospital Association, Part II, Vol. 34 (August 1, 1960), pp. 366-367. 
of mental illness and tuberculosis. The private sector, two-thirds of hospitals with one third of beds, is almost entirely under voluntary, nonprofit auspices; only 3 per cent of hospital beds are operated for profit. It thus comes about that social control of hospitals, whether through official or nongovernmental agencies, is nearly complete. It is true that many community hospitals are, in effect, dominated by their medical staffs, and here the extent of operative social control is minimal. Nevertheless, the legal basis for such control exists and could be more vigorously implemented.

Like all other components of our medical care establishment, the distribution of hospitals is far from equitable. Wealthy communities are better provided than those less endowed; and urban areas have many more hospital beds than the rural.

In 1946 the Hospital Survey and Construction Act (Hill-Burton) was adopted in an effort to correct the deficit in hospital facilities that had occurred during the lean years of the Depression and World War II. By requiring state-wide planning and a regional distribution of general hospital beds, it was hoped to achieve some reasonable correspondence between need and supply. More than ten years and $\$ 3$ billion later much remains to be done. ${ }^{15}$ It is true that acceptable general hospital beds on a nationwide basis have increased from 2.8 per 1,000 population to 3.4 per 1,000 and that the number of persons living in areas with no acceptable general hospital beds has been reduced from ten million to three. But with respect to

\footnotetext{
15 As of June 30, 1957, a total of 3,514 projects had been approved at an estimated cost of $\$ 2,874,587,085$, the federal share being $\$ 902,894,163$. Council on Medical Service, American Medical Association; The Hill-Burton Study: A Review of the Hospital Survey and Construction Act Since 1946 (Chicago: The Association, 1958), p. 2.
}

other kinds of hospital beds and related facilities, we seem to be little if any better off. Population growth and obsolescence of facilities have virtually neutralized the gains achieved through new construction. The Public Health Service estimates that, in order to maintain our present position and make some modest gains during the next ten years, we would need to construct 81,500 general hospital beds each year at a cost of $\$ 1,490$ million annually. ${ }^{16}$ Currently, our most urgent needs are for chronic hospital beds, of which we now have only 14 per cent of estimated requirements, and for nursing home beds, which now meet only 26 per cent of our estimated needs for acceptable accommodation. ${ }^{17}$

In recent years we have witnessed increasing public and professional acceptance of the hospital as the major focus of medical care. During the last thirty years, annual admissions to general hospitals have increased from 59 to 99 per 1,000 population, but, because hospital stay per admission has been considerably reduced, total days of hospital care have increased only from 746 to 851 per 1,000 persons per year. ${ }^{18}$ Between 1945

${ }^{16} \mathrm{~J}$. C. Haldemann, "Here Are the Goals for Health Construction," Modern Hospital; Vol. 93 (Oct. 1959), pp. 70-74.

17 Percentages are existing "acceptable" beds as percentage of total beds or units allowed by state ratios under the Hill-Burton Program as of January 1, 1958. Leslie Morgan Abbe, Anna Mae Baney, The Nation's Health Facilities: Ten Years of Hill-Burton Hospital and Medical Facilities Program, 1946-1956 (Public Health Service Publication No. 616) (Washington: U. S. Government Printing Office, 1958), p. 180; see also pp. 24, 34, 54.

${ }^{18}$ U. S. National Health Survey, Health Statistics: Hospitalization, Patients Discharged from Short-Stay Hospitals, United States, July 1957-June 1958 (Washington: U. S. Government Printing Office, 1958), p. 7, and Committee on the Costs of Medical Care, The Incidence of Illness and the Receipt and Costs of Medical Care Among Representative Families (Chicago: University of Chicago Press, 19.33), p. 113. 
and 1958, outpatient department visits increased by 128 per cent and emergency room visits by 120 per cent. ${ }^{19}$ The increasing use which the public makes of the hospital emergency room, to some extent a substitute for a physician's care in his office and the patient's home, has been the subject of study and comment both here and abroad. ${ }^{20}$

The increasing cost of hospital care is causing much concern. Between 1946 and 1959 , cost per patient day in general hospitals ${ }^{21}$ increased threefold, from an average of $\$ 10$ to $\$ 31$ per day. Despite shortening of hospital stay in this period, cost per hospitalized case was more than doubled. The price of hospital care is by far the most rapidly rising component of the medical care price index. $^{22}$ Between 1939 and 1959, there was a 317 per cent increase in the price of hospital care, compared to a rise of 73 per cent in general practitioners' fees, 68 per cent in surgeons' fees and 47 per cent in the price of drugs. Because of both increased utilization and increased price, the hospitals' share of the medcial care dollar has increased from nineteen cents in 1952-1953 to twenty-three cents in 1957-1958. ${ }^{23}$ In

19 Paul A. Skudder, James R. McCarroll, Preston A. Wade, "Hospital Emergency Facilities and Services, A Survey," Bulletin of the American College of Surgeons, Vol. 46 (MarchApril 1961), p. 49.

20 Ernest C. Shortliffe, T. Stewart Hamilton, Edward H. Noroian, "Emergency Room and the Changing Patterns of Medical Care," New England Journal of Medicine, Vol. 258 (Jan. 2, 1958), pp. 20-25, and Lionel Fry, "Casualties and Casuals," Lancet (January 16, 1960), pp. 163-166.

21 "Voluntary short-term general and special" hospitals.

22 Arthur Kemp, Walter R. Livingston, "Medical Care Costs in an Extended Inflation," Journal of the American Medical Association, Vol. 174 (October 29, 1960), p. 1213.

23 Health Information Foundation, "Our Increased Spending for Health," Vol. 9 (July 1960). view of these increasing costs, regulation of hospital utilization is assuming urgent importance. There are fears that present health insurance mechanisms, designed mainly to cover hospital care and geared to the solo, fee-for-service pattern of practice, tend to encourage hospitalization. In all age groups and over a wide range of family income, persons with health insurance use more hospital care than persons without. ${ }^{24}$ When a broad range of services for ambulatory patients is provided under the auspices of prepaid group practice, hospitalization seems to fall below the prevailing level in comparable population groups with equally liberal insurance benefits but receiving care through traditional forms of practice. ${ }^{25}$

Another major problem faced by hospitals is adequate staffing. Nursing shortages remain acute. The supply of resident physicians is so far below our requirements that we have attracted a large number of foreign physicians to help man our hospitals. Currently, a fifth of all positions for interns and residents are held by foreign graduates. In spite of this, 15 per cent of available positions remain vacant. The picture is much more dismal in certain parts of the country and for certain medical specialties. For example, in New Mexico, about 60 per cent of internships are unfilled; in North Dakota, 75 per cent of residencies remain vacant. In the entire country, graduates of foreign medical schools occupy 30 per cent of residencies in anesthesiology; 35 per cent in pathology; 41 per cent in cardiovascular disease; 51 per cent in general practice;

\footnotetext{
24 Maurice E. Odoroff, Leslie Morgan Abbe, "Use of General Hospitals: Variation with Methods of Payment," Public Health Reports, Vol. 74 (April 1959), pp. 321, 323.

25 Odin W. Anderson, Paul B. Sheatsley, Comprehensive Medical Insurance: A Study of Costs, Use, and Attitudes Under Two Plans (New York: Health Information Foundation, 1959), p. 36.
} 
and 65 per cent in pulmonary disease. ${ }^{26}$

Ordinarily, one would view with satisfaction the contribution our hospitals seem to be making to the training of foreign physicians. There are, however, questions concerning the adequacy of the educational experience which some hospitals are able to provide the foreign graduate. At the same time, there is serious doubt about the ability of many foreign physicians both to benefit from the educational opportunities offered and to carry the responsibilities thrust upon them for the care of the sick. ${ }^{27}$

It is clear that the answer to the problem of staffing our hospitals cannot be found in traditional ways. We now have more internships than we expect to have medical school graduates in 1975 even under an expanded program of medical education. If it is true "that many more physicians are required by the hospitals each year than are needed by the country as a whole," ${ }^{28}$ some bold departures are necessary to insure adequate care for the hospitalized patient, as, indeed, for the community as a whole.

One response to these pressures is increasing concern about the most efficient

26 "34th Annual Report on Graduate Medical Education in the United States," Journal of the American Medical Association, Vol. 174 (October 8, 1960), pp. 579, 580.

${ }_{27}$ The Educational Council of Foreign Medical Graduates (sponsored by the American Medical Association, American Hospital Association, Association of American Medical Colleges and Federation of State Medical Boards) was founded in October 1957 with a view to introducing some measure of control over the qualifications of foreign physicians seeking training in this country. In examinations held so far, about half of physicians already placed in our hospitals have failed to qualify. Should these physicians lose their positions, as the Council demands, about 25 per cent of all approved internships and residencies would become vacant.

28 "The Foreign Medical Graduate," New England Journal of Medicine, Vol. 264 (March 2, 1961), pp. 461-462. methods for providing care within hospitals. Even the most cursory observation will show that not all hospitalized patients need the same intensity of nursing and medical supervision. It should be reasonable, therefore, to classify patients according to their needs for care and to adapt hospital facilities and services accordingly. This is the principle underlying the scheme of progressive patient care which has recently attracted much attention. ${ }^{29}$ Where this system of graded patient care has been adopted, the institution is divided into four units, each planned, equipped, and staffed to maintain a different level of care. These are a special care unit for critically ill patients irrespective of age, sex, or diagnosis; an intermediate care unit for the less critically ill; a self-care unit for patients who are able to care for most of their personal needs; and a continuation care unit for patients suffering from chronic illness and disability and whose major needs are for rehabilitation. Whether this arrangement will help control the rise in hospital costs, as its advocates claim, or insure a greater return for the hospital dollar remains to be seen. Certainly it has implications for improving patient care far beyond possible influence on costs.

Another trend with possible far-reaching implications for the future is the extent to which community health services and facilities may cluster in and around the general hospital. We are witnessing a move away from specialized hospitals in favor of providing a wide range of services within the general hospital. Many general hospitals now provide care for patients with shortterm mental illness, for tuberculosis and infectious diseases. The Commission on Chronic Illness has recommended that

${ }^{29}$ Howard J. Lockward, Lane Giddings, and others, "Progressive Patient Care," Journal of the American Medical Association, Vol. 172 (January 9, 1960), pp. 132-137. 
care for long-term patients be provided "through extension, organization and coordination of the facilities and services of general hospitals. . . . The independent chronic disease hospital is a second choice approach to long-term hospital care." 30

For reasons of convenience, many physicians locate their offices near the general hospital where so much of their work is done. Some hospitals lease office space on their premises to physicians on their staff with advantages to both hospital and physician. In a few instances, the local health department has been housed either in the same building as the hospital or in a separate building on the same grounds.

Concurrent with these developments, the general hospital is just now beginning to realize its responsibilities for medical care in the community. Somewhat hesitantly but along several fronts it has extended its extramural services. The broadening scope and increasing use of outpatient and emergency room services is one expression of this trend. Another is the development of organized home care programs supported and supervised by the hospital. Still another is the establishment of relations with nursing homes and other institutions for the care of long-term illness.

Organized home care programs rest on the premise that in many instances hospitalization may be shortened or altogether avoided, with the patient's interests as well or better served, if medical and nursing care, together with the necessary supportive services, are made available in his home. Because such programs are still so few in number, their total impact has thus far been very small. ${ }^{31}$ Nevertheless, potentially they

30 Commission on Chronic Illness, Chronic Illness in the United States, Vol. II: Care of the Long-Term Patient (Cambridge: Harvard University Press, 1956), pp. 186-187.

31 In 1960 the Public Health Service and the American Hospital Association identified over offer one eminently reasonable alternative to the excessive institutionalization of the chronically ill. As such, they may yet come to occupy an important place in a structure of interrelated services that must be built in order to meet the increasing burden of chronic illness and disability. But, before this happens, two major obstacles must be overcome. Adequate sources of financing, in addition to public assistance funds and foundation support, must be secured, and some way must be found to bring about the participation in home care programs of physicians in private practice on behalf of their patients.

During the last two decades, nursing homes have come to occupy a very important position among the resources available for the care of the chronically ill and disabled. As of July 1960, there were 307,681 beds in homes offering skilled nursing care, but of these only 44 per cent were rated as acceptable. ${ }^{32}$ Quite unlike hospitals, the vast majority of these homes are privately owned and operated for profit. The proprietary nursing home is typically a small institution with an average size of twenty beds and is often a converted old home with generally inadequate facilities and services. Surveys of the nursing home population have revealed an astounding picture of disease and disability. ${ }^{33}$ In rather pitiful contrast are

forty comprehensive care programs and about twenty-five others offering limited service. David Littauer, I. Jerome Flance, Albert F. Wessen, Home Care (Hospital Monograph Series No. 9) (Chicago: American Hospital Association, 1961), p. 5.

32 U. S. Senate Committee on Labor and Public Welfare, The Condition of American Nursing Homes (Washington: U. S. Government Printing Office, 1960), p. 8.

33 See, for example, Jerry Solon, Dean W. Roberts, and Others, Nursing Homes, Their Patients and Their Care: A Study of Nursing Homes and Similar Long-Term Care Facilities in 13 States (Public Health Monograph No. 46) (Washington: U. S. Government Printing Office, 1957), pp. 10-21. 
the meager resources available to the average nursing home for meeting these needs. One survey showed that almost 60 per cent of the homes presumably providing skilled nursing care had no registered nurse on the staff, and 40 per cent of the patients had not been seen by a physician during the previous month. ${ }^{34}$ While many nursing homes do the best they can with the limited resources at their disposal, very few offer the range of therapeutic and restorative services required for optimal care. It is in this context that the role of the general hospital should be viewed. Ideally, relationships should be such that the hospital can provide effective medical and nursing supervision in the nursing home. Given the large number, small size, and proprietary ownership status of most of our nursing homes, the relationships suggested above may not be feasible. It may only be possible through the development of a system of nonprofit nursing homes associated with our voluntary hospitals. Matching funds for the construction of such facilities have been available since 1954 through the Hill-Burton program.

The need for establishing meaningful relationships between hospitals and nursing homes is only one instance of a larger problem that we now face, namely bringing together in some rational system of organization the large number of separate medical care institutions and services in the community. The regional organization of hospitals is one device advocated to help accomplish this objective. In its pure form, this concept envisages the unified planning of a functionally differentiated and carefully coordinated system of hospitals serving an entire geographic region demarcated, not by narrow political boundaries, but according to established patterns of seeking and providing medical care in a manner analogous to trading areas. Un-

${ }^{34}$ Ibid. der such a plan, standards of medical care could be considerably improved throughout the region without costly duplication or inefficient deployment of scarce resources and skills. There would be established appropriately located central or base hospitals to which the other smaller hospitals in the region would turn for help and advice. The central hospital would in turn assume considerable responsibility for supporting continuing professional education and medical and allied services in the hospitals associated with it. Although such proposals appear to be eminently reasonable, they run counter to many deeply rooted traditions in our national life. Consequently, examples of regional hospital organization are very few in this country. ${ }^{35}$

\section{Conclusions}

It is apparent from the foregoing that a major characteristic of the organization of medical care in this country is its lack of organization. In spite of the multiplicity of governmental and privately sponsored programs, important areas of need remain virtually untouched. Everywhere one is confronted with shortages, maldistribution, haphazard growth, and inefficient use of scarce and valuable resources. What is required is a broad, flexible, and carefully co-ordinated system in which appropriate services are readily available and continuously adapted to the patients' needs. Ambulatory care in the physician's office or outpatient clinic; outpatient diagnostic services; progressive inpatient care; home care fully supported by the resources of the hospital and community; adequately supervised

${ }^{35}$ For a description of one such program, see Leonard S. Rosenfeld and Henry B. Makover, The Rochester Regional Hospital Council (Cambridge: The Commonwealth Fund, Harvard University Press, 1956). 
and restoratively oriented nursing home care-all these, together with a variety of supportive services, would present a wide choice of alternatives with unhampered movement from one to the other. The voluntary hospital, because it represents the richest and most highly organized store of medical skills in the community and because it is most readily amenable to professional and social control, might well become the nucleus around which such a system could be built with least modification of prevailing patterns of medical care. Crucial to this development is a method of financing medical care which, unlike present methods with their emphasis on hospitalization, would adequately support the broad range of services required for comprehensive care. 